\title{
LA VOLUNTAD DEL LEGISLADOR: GENEALOGÍA DE UNA FICCIÓN HERMENÉUTICA
}

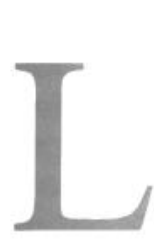

s incertidumbres y las opacidades que se derivan de la textura
abierta del derecho no pueden ser reducidas a partir de las re-
glas del uso ordinario del lenguaje, ni tampoco a partir de la ex-
plicitación de una gramática del lenguaje jurídico 1 . Pero aun-
que parezca cierta la existencia de un margen de ambigüedad o imprecisión irreductible, los juristas no han renunciado nunca al postulado de la existencia de un único resultado correcto, esto es, a un ideal de certeza. Sólo desde fechas relativamente recientes se reconoce una cierta holgura hermenéutica y se prevé la necesidad de recurrir a reglas y criterios adicionales para reducir los márgenes de discrecionalidad resultantes. Hoy en día, incluso, esta economía de la imprecisión, o mejor, los márgenes de flexibilidad dogmática que genera esta holgura hermenéutica tienden a verse como algo positivo y las reglas y criterios desde los que se administra la imprecisión se conciben en buena medida como algo ajeno a la ley (construcciones dogmáticas, criterios axiológicos, valores superiores, argumentación racional, formas de vida, etc.). Pero lo característico de la concepción tradicional que domina la ciencia jurídica hasta comienzos de siglo y que todavía hoy conserva una cierta lozanía en la dogmática jurídica era precisamente el desconocimiento, o mejor, el enmascaramiento de la existencia de ese margen de flexibilidad dogmática, con lo cual la justificación hermenéutica quedaba envuelta en un halo de misterios y ficciones.

La concepción tradicional identifica la labor hermenéutica como una tarea tendente a descubrir el significado de la ley. Con mayor precisión, la actividad hermenéutica estaría encaminada a descubrir un sentido objetivo depositado en la letra de la ley. Este significado, que acompañaría espiritualmente al texto, consistiría en un contenido intelectual que traduce la voluntad del legislador o el pensamiento racional de la ley. Con la consolidación científica de la dogmática jurídica, esta concepción se ha fragmentado. Así, junto a la concepción de ese sentido objetivo como la voluntad del soberano que caracteriza las teorías del positivismo imperativista, comienza a hablarse, o mejor, se recupera una terminología que identifica ese sentido

Cfr. Herbert L. A. HART, «Separación entre derecho y moral», en Derecho y moral. Contribuciones a su análisis, trd. G. R. Carrió, Buenos Aires, Depalma, 1962, pp. 25 ss.: ID., The Concept of Law, Oxford, Clarendon Press, 1972, pp, 121 ss.; Genaro R. CARRIÓ. Notas sobre derecho y lenguaje, Buenos Aires, Abeledo-Perot, 1973, pp. 44 ss. La noción de «textura abierta» es aún más radical que la de «vaguedad»,"cfr. Friedrich WAISSMANN, «Verificabilidad», en La teoría del significado, G. H. Parkinson (Ed.), trd. Paloma Villegas, México; FCE, 1976, p. 62: «la textura abierta es algo así como la posibilidad de vaguedad. La vaguedad puede ser remediada con reglas más precisas, pero la textura abierta no puede serlo». 
objetivo con el pensamiento de la ley ${ }^{2}$. De todas formas, en ambos casos, el sentido objetivo de la ley se identifica con una instancia mental, algo que ha sido concebido o pensado y que se transmite a través de las palabras. Con el fin de simplificar la terminología que voy a usar, denominaré «semántica de la voluntad» a las hipótesis filosófico-lingüísticas sobre las que se apoya esta concepción y hablaré de «voluntad del legislador» en un sentido amplio para comprender las versiones que identifican esa instancia racional profunda con el pensamiento de la ley o la ratio scripta.

Según esta concepción, a la que podemos seguir denominando tradicional, el experto o intérprete autorizado administra las posibles imprecisiones del texto legal mediante recursos hermenéuticos y argumentos que se apoyan en la presuposición de que el significado de la ley es siempre racional y perfecto. La unidad del derecho que presupone la semántica de la voluntad determina la racionalidad del contenido profundo de la ley. Las posibles contradicciones serían sólo aparentes, no reales. El postulado de la voluntad del legislador permite al intérprete superar las imprecisiones, los silencios e, incluso, las contradicciones entre lo que expresa el tenor literal de la ley y lo que el intérprete piensa que debería haber sido querido por un legislador racional corriendo e integrando sistemáticamente la ley. Si se presume que el significado profundo de la ley es racional, cualquier especificación de ese significado que se aparte de los cánones de racionalidad del orden dogmático de la ley debe ser rechazada como un error y procederse a restaurar la racionalidad del significado de la ley corrigiendo, incluso, su tenor literal. Si bien las referencias próximas de esta concepción pueden encontrarse incluso en la ciencia jurídica actual ${ }^{3}$, las raíces y, hasta cierto punto, las razones de la misma han de buscarse mucho más lejos. Sólo indagando en los estadios iniciales del desenvolvimiento de esta idea descubriremos plena y nítidamente su valor, esto es, hallaremos el valor de la misma ligado a construcciones teóricas no sofisticadas, construcciones que aún no se han

2 Esta distinción es importante en tanto en cuanto desde el siglo XIX va a enfrentar en la ciencia jurídica dos teorías de la interpretación. La primera de esas dos corrientes sostiene que el intérprete ha de buscar la voluntad de hecho del legislador histórico; mientras que la segunda, la llamada teoría objetiva de la interpretación, busca el significado racional inmamente de la ley con independencia de la intención del legislador histórico. Cfr., al respecto, Karl LARENZ, Metodología de la ciencia del derecho, 2 a $^{\text {a }}$ ed., trd. M. Rodríguez Molinero, Barcelona, Ariel, 1980, pp. 53 ss. y 312 ss.

Sobre la prevalencia del significado profundo sobre el significado literal en la dogmática actual, pueden verse, por ejemplo, José PUIG BRUTAU, Introducción al Derecho civil, Barcelona, Bosch, 1981, pp. 307 ss.; Carlos de la VEGA BENAYAS, Teoría, aplicación y eficacia de las normas en el Código civil, Madrid, Civitas, 1979, p. 122 ss. La hipótesis voluntaristas, ya como concepción subjetiva o como concepción objetiva, mantiene su presencia aún en la doctrina, cfr. José CASTAN TOBEÑAS, Derecho Civil Español, Común y Foral, tomo I, vol. I, 1 1. a ed., rev. J. L. de los Mozos, Madrid, Reus, 1975, p. 523 ss.; Luis DÍEZ PICAZO, Experiencias jurídicas y teoría del derecho, Barcelona, Ariel, 1973, pp. 243 ss.; Jose LACRUZ BERDEJO, Elementos de Derecho civil, tomo I, vol. I, Barcelona, Bosch, 1982, pp. 240 ss. De algún modo, también pueden considerarse como variantes de la semántica voluntarista todas las teorías actuales que partes del postulado de la racionalidad del legislador. Sobre estas teorías puede verse mi trabajo «Metodología e interpretación: el postulado de la racionalidad del Legislador», que aparecerá en el número 3 del Anuario de Filosofía del Derecho (1986). 
impregnado de la necesaria ambigüedad que el paso de los tiempos deposita en las mismas como canon para su supervivencia. Por eso, en este trabajo, me propongo revisar la genealogía de esta ficción hermenéutica desde sus orígenes filosófico-linguiísticos y teológicos hasta Bentham. Saltando sobre las transformaciones y la fragmentación actual de la concepción tradicional, se estudiará el valor de la «semántica de la voluntad» en sus orígenes y en el desarrollo de la misma. En el primer apartado, esta revisión hará especial hincapié en las explicaciones dogmáticas de Agustín de Hipona. De hecho, entiendo que a los juristas medievales y humanistas el esfuerzo ideológico para justificar la pureza de las interpretaciones y la literatura exegética del Corpus Iuris les viene dado desde fuera. Concretamente, desde el nuevo talante hermenéutico que inaugurara Agustín de Hipona para conciliar las exigencias dogmáticas de fidelidad al Texto con la superación canónica de las dificultades que suscita su propuesta de retorno a la escritura. En un segundo apartado, repasaré brevemente las inflexiones racionalistas del mito hermenéutico de la voluntad del legislador para detenerme, por último, en el tercer apartado, en la síntesis moderna de Bentham. Un autor de transición en el que culminan las concepciones nacionalistas y la voluntad del legislador se identifica definitivamente con un contenido semántico que consistiría en ideas abstractas, auténtico fundamento de una ideología hermenéutica que se caracteriza por su fe en la deducción.

En la metodología de la concepción tradicional, la «semántica de la voluntad» se configura como el dato fundamental para la justificación de las decisiones hermenéuticas. A partir de esta ideología semántica, se hace transcender la objetividad de la interpretación ligándola a un significado profundo cuya autoridad sería incontestable. Al identificarse el sentido objetivo depositado en la letra de la ley como la voluntad del legislador o una instancia racional profunda, la interpretación autorizada o correcta expresaría sin opacidad ni distorsión alguna el pensamiento o la voluntad incorporada como instancia espiritual al texto, a la letra de la ley. En el fondo de este postulado, late una concepción semántica que identifica el significado de las palabras con la expresión de un pensamiento. El punto de referencia último de esta forma de concebir el significado de las palabras puede rastrearse hasta la ordenación aristotélica de los signos a la expresión de un pensamiento ${ }^{4}$; pero de cara a comprender y valorar su transcendencia en las jurisprudencia medieval y moderna es necesario contrastar su desenvolvimiento con la renovación del canon hermenéutico teológico que lleva a cabo Agustín de Hipona.

Para Agustín de Hipona, todo signo está siempre en lugar de algo y eso que denota el signo es precisamente su significado ${ }^{5}$. Partiendo de esta de-

${ }^{4}$ ARISTÓTELES, De la interpretación, en Obras, trd. P. Samaranch, Madrid, Aguilar, 1977, p. 256 (16.a).

5 AGUSTÍN DE HIPONA, De Doctrina Christiana, en Obras, vol. XV, ed. B. Martín, Madrid, BAC, 1969, I. 2.2.; II. 1. 1. 
finición, observa que los signos convencionales sirven para manifestar externamente los «movimientos del alma». Tales signos y, particularmente, las palabras tendrían un uso comunicativo propio: «sacar y trasladar al ánimo de otro lo que tenía en el suyo aquél que dio tal señal» ${ }^{6}$.

Sobre la base del reconocimiento, aparentemente neutro, de considerar que el significado es aquello en lugar de lo que está el signo, aquello que denota el signo o aquello que hace venir al pensamiento el signo, Agustín de Hipona sienta las bases para la conformación de un nuevo talante hermenéutico. La importancia de la inflexión hermenéutica agustiana no sólo ha despertado la atención de los teólogos. Gadamer, por ejemplo, destaca el carácter de reflexión de segundo orden que conlleva el giro de Agustín de Hipona al intentar superar las dificultades del método alegórico de la teología romana para solventar las ambigüedades y las contradicciones del Texto sagrado ${ }^{7}$. En realidad, opino que la importancia del giro agustiniano no ha de buscarse sólo en su intento de reconducir por los caminos de la verdad dogmática la reexposición del Texto. Al respecto, hay que destacar el dato, importante en su construcción y en la de cualquier orden dogmático, de la posibilidad de conciliar la certeza absoluta con la existencia de unos ciertos márgenes de libertad dogmática en la justificación hermenéutica. Dado que el significado liga la palabra sagrada a la voluntad de Dios, quien está llamado el Texto sagrado no ha de encontrar en él «más que el pensamiento y la voluntad de los que lo escribieron», para de este modo llegar a conocer la voluntad de Dios según la cual hablaron aquellos hombres ${ }^{8}$. De esta manera, la actividad hermenéutica se justifica hacia adentro, dando lugar a dos consecuencias importantes. En primer lugar, aunque articulada superficialmente, la justificación se vuelve profunda por mor de la conexión significadopensamiento. Con ello, no se trataría sino de inscribir la re-exposición hermenéutica directamente, sin opacidades ni interferencia alguna, en la autoridad del «editor». En segundo lugar, se cierra el círculo que hace de la voluntad divina el centro omnipresente desde el que se organizan y administran las soluciones terrenales.

El talento hermenéutico que hemos reseñado, encuentra una específica caja de resonancia en la jurisprudencia medieval y humanista ${ }^{9}$. En el ámbito de la ley, el pensamiento, la racionalidad profunda de la ley, dispone la objetividad y las soluciones en torno a un centro adimensional, profundo, la razón jurídica, desde el que se organizan la letra de la ley y la actividad hermenéutica de los iustitiae sacerdotes, esto es, unas determinadas re-

6 Ibídem, II .2. 3. Cfr., con anterioridad, AGUSTÍN DE HIPONA, Confesiones, en Obras, vol. II, ed. A. Custodio, Madrid, BAC, 1951, I. 8. 13.

7 - Hans G. GADAMER, «Hermenéutica como filosofía práctica», en La razón en la época de la ciencia, trd. E. Garzón, Barcelona, Alfa, 1976, pp. 64-5; también apunta su interés en GADÁMAR, Verdad y método. Fundamentos de una hermenéutica filosófica, 4. ${ }^{a}$ ed.. trd. Ana Agud y R. Agapito, Salamanca, Sígueme, 1977, p. 225.

8 AGUSTÍN DE HIPONA, De Doctrina Christiana, cit., II. 5. 6.

9 Al respecto, puede verse Vicenzo PIANO MORTARI, Dogmatica e interpretazione. I giuristi medievali, Napoli, Jovene, 1976; en particular sobre la asunción de la concepción del significado de la patrística en la jurisprudencia medieval, cfr. pp. 174 ss. 
laciones de saber y poder que en todo caso hemos de situar en el universo de las culturas del libro ${ }^{10}$. La existencia de un Texto en el que la letra es, al mismo tiempo, centro integrador y verdad definitiva requiere un canon hermenéutico en el que se presuponga la univocidad significativa de la expresión. La custodia de la pureza y la univocidad de su contenido requiere, además de la preeminencia de una casta espiritual que fije canónicamente el propio Texto y la literatura exegética ${ }^{11}$, un esfuerzo ideológico que justifique la propia posibilidad de la objetividad hermenéutica ante las dificultades -contradicciones, vaguedad, etc.-, del Texto. En este punto, resulta particularmente importante la inflexión hermenéutica de Agustín de Hipona. La exigencia de la fidelidad al Texto invalida la interpretación alegórica, pero el retorno a la fidelidad al Texto resucita viejas dificultades. La importancia de la inflexión hermenéutica a la que se acaba de hacer referencia radica en el hecho de que aborda directamente las dificultades derivadas de la interpretación literal del Texto. Con su empeño, casi patológico, en la búsqueda de una verdad absoluta, Agustín de Hipona perfila eficazmente el norte apropiado para un talante hermenéutico que pretende al mismo tiempo la flexibilidad racionalizadora de la interpretación y el respeto a la literalidad del Texto. De ahí, precisamente, su amplia repercusión en la jurisprudencia medieval. La voluntad de Dios -o, en su caso, la ratio scripta o la intención del legislador-, que es lo que significa el Texto, se constituye en una especie de centro hermenéutico interno, profundo, capaz de producir un sentido objetivo que, en caso de hacerse necesario, pueda corregir la literalidad inmediata, los defectos atribuibles o localizados en la expresión de los pensamientos mediante los signos escritos. Se trata de un centro espiritual que no sólo sobre-codifica y armoniza la pluralidad de las lecturas que se realizan, sino que además legitima cualquier reproducción hermenéutica autorizada más allá e, incluso, frente a la letra muerta. Así, Agustín de Hipona sostiene que «todos los que leemos nos esforzamos por averiguar y comprender lo que quiso decir el autor que leemos, y cuando lo creemos veraz, no nos atrevernos a afirmar que haya dicho nada de lo que entendemos o creemos que es falso». De igual modo, añade, «ocurre cuando alguno se esfuerza por entender en las Sagradas Escrituras aquello que intentó decir en ellas el escritor» ${ }^{12}$. En este mismo sentido, la tarea del jurista, tal y como era entendida por los juristas medievales y humanistas, consistiría en reconocer y declarar el sentido objetivo de la ley, su valor racional: bien que se mostrase directamente en el sentido literal del texto o bien que, resultando idóneo el sentido literal según los parámetros de la racionalidad dogmática, hubiera de procederse a indagar, con la ayuda de los procedimientos herme-

10 En este sentido, Manuel GARCÍA PELAYO, Las culturas del libro, Caracas, Monte Ávila, 1976, p. 9 ss. Desde una perspectiva distinta, son interesantes algunas de las observaciones de Pierre LEGENDRE, El amor del censor. Ensayo sobre el orden dogmático, trd. Marta Giacomino, Barcelona, Anagrama, 1979, p. 85 ss.

11 GARCÍA PELAYO, Las culturas del libro, cit., p. 37; ID., El Reino de Dios, arquetipo político. Estudio sobre las formas políticas de la Alta Edad Media, Madrid, Rev. de occidente, 1959, pp. 218 ss.; LEGENDRE, El amor del censor, cit., pp. 106 ss.

12 AGUSTÍN DE HIPONA, Confesiones, cit., XII. 18. 27. 
néuticos admitidos, cuál sería el significado adecuado al espíritu racional que alienta en las profundidades de la expresión lingüística ${ }^{13}$.

\section{II}

La modernización de la sociedad y el racionalismo inciden sobre la metodología jurídica renovando sustancialmente aspectos fundamentales de la misma. La conjunción de diversos factores como el proceso de estatalización de la ley y la consiguiente superlegitimación de la misma como fuente del derecho, la resolución imperativista del positivismo y un racionalismo constructivo incipiente implementan la vieja idea fundante de la semántica de la voluntad. Por otro lado, la aparición del elemento sistemático, su matematización y la proposicionalización de la verdad refuerzan las posibilidades de auto-integración de la ley. Aunque la ciencia jurídica de la época no está todavía en condiciones de superar las instancias transcendentes de integración, se muestra con claridad la pujanza de nuevas formas de proceder y algunos postulados que hacen posible la auto-integración hermenéutica de la ley y la autonomía de lo jurídico. El voluntarismo moderno, racionalista, traduce la fe política de las nuevas clases dominantes en la seguridad y la capacidad creadora de la letra escrita. Así, progresivamente, se van consolidando las explicaciones que pretenden integrar la ley autonómamente. Esto conlleva la necesidad de dotar a la escritura de una capacidad ideológica suficiente para fijar terminantemente el espíritu de la ley, eludiendo la arbitrariedad e identificando el mandato del legislador como la manifestación asertiva de un contenido volitivo.

La precipitación de las teorías y la tradición dogmática en la obra de Hugo Grocio ofrece un interés singular de cara a valorar concretamente las apreciaciones generales que se acaban de hacer ${ }^{14}$. Por otro lado, en la obra de Grocio encontramos uno de esos casos paradigmáticos en los que la evidencia de una concepción semántica se resalta con especial nitidez precisamente por el hecho de darse por descontado. Así, no encontramos propiamente una teoría -del significado de la ley. La noción de significado que se

13 PIANO MORTARI, Dogmatica e interpretazione, cit., p. 179: ante el supuesto de inidoneidad del sentido literal, «el intérprete no debería dudar en descartar el significado propio de la palabra de una ley y seguir aquel otro que aun impropio literalmente, fuese más adecuado al espíritu del precepto».

14 Cfr. Hugo GROCIO, De Iure Belli ac Pacis, B. J. A. de Kanter-van Hettinga Tromp (Ed.), Lugduni Batavorm, E. J. Brill, 1939 (hay una traducción castellana incompleta de J. Torrubiano: Del Derecho de la Guerra y la Paz, Madrid, Reus, 1925). La fortuna de su obra De Iure Belli ac Pacis ha hecho que Grocio haya sido considerado generalmente como el iniciador o figura fundamental del iusnaturalismo racionalista moderno. Lo cual, por una parte, ha servido para eclipsar la labor de otros juristas de la época y, por otro lado, generó una impresión de ruptura que no es tal. Es este sentido, cfr. Francisco CARPINTERO, «'Mos italicus', 'mos gallicus' y el Humanismo jurídico racionalista. Una contribución a la historia de la metodología jurídica», Ius comune, VI, Frankfurt, a. M., Klostermann, 1977, p. 170: «Grocio se muestra un continuador de aquella jurisprudencia del 'Derecho común' remozada por el Humanismo que, escéptica ante la validez del Derecho romano, tuvo que recurrir para crear Derecho a la razón humana, que en ella se despliega de forma más libre que en la jurisprudencia anterior». 
ha descrito en el apartado anterior tiene ya tanta fuerza que su presencia queda oculta en el transfondo de la mirada del conocer. La semántica de la voluntad esta ahí y aflora cuando se recurre a ella como argumento o cuando sirve para esclarecer la relación entre la voluntad y lo declarado, aspecto en el que Grocio es heredero en buena medida de los planteamientos de la escuela española ${ }^{15}$. De la misma forma, se hace presente allí donde se ocupa del dolo y la mentira, dado que para Grocio el concepto de verdad sigue vinculado a la correspondencia entre lo expresado, la declaración, y el estado anímico, los conceptos de la mente ${ }^{16}$.

Los postulados metodológicos de su teoría de la interpretación también se inscriben en la tradición hermenéutica que venimos considerando. Quizá por el hecho mismo de funcionar como bisagra hay un elemento que cobra una relevancia fundamental: el elemento sistemático. Aunque el concepto de sistema propio del racionalismo todavía no se encuentra en la obra de Grocio, sí es posible identificar la noción básica de un sistema integrador que hace posible completar o dar coherencia la voluntad que expresa el significado de las normas jurídicas mediante «conjeturas»-coniuncta. La razón de ser o la necesidad de esta interpretación integradora surgiría de la ambigüedad o polisemia de las palabras; de la idea repugnante -para la razón- a que pudiera conducir la estricta literalidad o, también, del hecho de que sin esta interpretación pudiera llegarse a soluciones contradictorias ${ }^{17}$. En la teoría hermenéutica de Grocio, la «integración conjetural» se saca principalmente «por las materias, por el efecto y por las conexiones -coniunctis- ». A su vez, estas conexiones o «relaciones entre sí» podrían derivarse por razón de su origen o por el lugar. En el primer caso, la razón de la conexión vendría dada por el hecho de la procedencia de una misma voluntad: «aunque dicho en otro lugar y con otra ocasión», la conjetura nace del hecho de que en la duda se cree «que la voluntad es coherente consigo misma» ${ }^{18}$. En el segundo caso, cuando la conexión tiene como razón el lugar, su explicación se articula a partir de la ratio legis. La cual no debe ser confundida con la intención del legislador, ya que ésta es sólo uno de los indicios por los cuales se alcanza la ratio legis ${ }^{19}$.

15 En este sentido, Franz WIEACKER, Historia del Derecho privado en la Edad Moderna, trd. F. Fz. Jordán, Madrid, Aguilar, 1957, p. 252.

16 GROCIO, op. cit., lib. III,,cap. I: X, 1; III, I: VII, 1 y XI, 1.

17 Ibídem, II, XVI; IV. Esta terminología precaria se mantiene hasta el siglo XIX. Savigny, por ejemplo, todavía se refiere a la integración sistemática de ordenamiento jurídico como un todo orgánico denominandola «crítica de conjetura» (Konjeturalkritik), cfr. Friedrich K. von SAVIGNY, Juristische Methodenlehre, Stuttgart, Koehler, 1951, pp. 20-1.

18 GROCIO, op. cit., II, XVI: IV-VII. La unidad de la mente humana es la hipótesis básica de la cual se parte. Se supone que la mente humana por ser de creación divina no puede contradecirse a sí misma. Esta hipótesis tiene gran importancia en la doctrina de la Iglesia y en el derecho de la Edad Media, cfr. Walter ULMANN, Historia del pensamiento político en la Edad Media, trd. Rosa Vilaró, Barcelona, Ariel, 1983, pp. 116 ss.

${ }^{19}$ GROCIO, op. cit., II, XVI: VIII. 
Sin embargo, a pesar de las resonancias actuales de todo lo dicho, el autor verdaderamente moderno no es Grocio, sino Thomas Hobbes. La ruptura de Hobbes con el «modelo aristotélico» de la justificación y la explicación del Estado ${ }^{20}$, le proporciona los instrumentos conceptuales necesarios para precisar la noción de ley como el mandato que traduce la voluntad del soberano $^{21}$. Así, la ley propiamente dicha, la ley civil, es un mandato que expresa la voluntad del soberano y que recibe su autoridad y la razón de su obediencia exclusivamente del hecho de representar la voluntad del soberano ${ }^{22}$. Esta concepción, con idependencia de que identifica un uso específico del lenguaje y liga el significado de la ley a un presupuesto de autoridad, va a generar consecuencias teóricas importantes. De entrada, se pasa a considerar que «el legislador no es aquél por cuya autoridad se hicieron incialmente las leyes, sino aquel otro por cuya autoridad continúan ahora siendo leyes» ${ }^{23}$. Pero junto a esta observación, hay otras que modernizan considerablemente el sentido objetivo que expresan las leyes y que se busca mediante la interpretación. En realidad, en este punto, la importancia del positivismo hobbesiano radica, principalmente, en el hecho de que se reorganiza, definitiva y autonómamente, la idea de un legislador racional que sintetiza poder, voluntad y razón. Una idea que late en los orígenes del mundo moderno como trasunto de la idea teológica de divinidad ${ }^{24}$.

Aparentemente, lo anterior no produce grandes cambios en el esquema de la interpretación. Al igual que antes, el significado de la ley no es la letra, sino lo que está de acuerdo con la intención del legislador. De la misma manera, la síntesis racionalista que se proyecta sobre la «intención del legislador» puede corregir el significado literal del texto. Igualmente, por fin, ese fatum profundo de racionalidad niega la pluralidad del texto y ampara la objetividad de las interpretaciones autorizadas. Sin embargo, estas viejas consecuencias aparecen ligadas a un fundamento nuevo. En este sentido, Hob-

20 Cfr. Norberto BOBBIO, Estudios de historia de la filosofía. De Hobbes a Gramsci, ed. A. Ruiz Miguel, trad. J. C. Bayón, Madrid, Debate, 1985, pp. 92 ss.

21 También contribuye a ello su concepción sobre el lenguaje. Ya en sus Elementos, Hobbes establece que uno de los usos específicos del lenguaje consiste en la expresión de la voluntad, cfr. Thomas HOBBES, Elementos de Derecho Natural y Político, trd. D. Negro, Madrid, CEC, 1979, p. 197.

22 Ibídem, pp. 197-8; también en HOBBES, Del ciudadano, trd. A. Catrysse, Caracas, IEP, 1966, pp. 217 s. Hobbes precisa el concepto de ley civil en el cap. 26 de la II parte del Leviatán, cfr. HOBBES, Leviatan o la materia, forma y poder de una República eclesiástica y civil, trd. M. Sánchez Sarto, México, FCE, 1980, p. 217 ss.

23 Ibídem, p. 220

24 Cfr. Enrique GÓMEZ ARBOLEYA, Estudios de teoría de la sociedad y del estado, Madrid, IEP, 1962, pp. 422,450; también en ID., Historia de la estructura y del pensamiento social, Madrid, I. E. P., 1976, p. 151: «La unidad política produjo la visión de la unidad jurídica. Aunque cada precepto nace en determinadas condiciones para ciertas necesidades, todos convergen en un vértice: en la voluntad del legislador. El legislador humano se ve investido con los atributos que antes se predicaban sólo del divino (...). La Teología había dicho que en Dios, infinitamente perfecto, son idénticas voluntad y razón. El jurista moderno sostiene implícitamente lo mismo del legislador humano. De aquí, que sus conceptos y construcción se convierten, en último término, en la mejor manera de explicitar aquella perfectísima voluntad». 
bes formula explícitamente y con gran fuerza su punto de partida: «la voluntad de otro no puede ser advertida sino por sus propias palabras o actos, o por conjeturas tomadas de sus fines y propósitos, lo cual en la persona del Estado debe suponerse siempre en armonía con la equidad y con la razón» ${ }^{25}$. Las razones de la coherencia sistemática de la ley son más profundas que las de Grocio. La representación del Estado como hombre artificial, expresión absoluta de la razón, y de la ley como la manifestación de su voluntad determinaría el hecho de que «no pueda surgir fácilmente una contradicción en las leyes»; y que «cuando ésta se produce, la misma razón es capaz, por interpretación o alteración, de eliminarla» ${ }^{26}$. Esta capital función integradora que se asigna a la interpretación repercute directamente en los postulados de la justificación hermenéutica. En primer lugar, Hobbes afirma que «no es en la letra, sino en la intención o el significado, es decir, en la interpretación auténtica de la ley -que estriba en el sentido del legislador- donde radica la naturaleza de la ley ${ }^{27}$. En segundo lugar, Hobbes hace derivar de lo anterior la dependencia estricta del interprete a la autoridad del soberano, que al mismo tiempo le autoriza y legitima en su labor. Así, considera que las sentencias, sobre todo las que interpretan la ley natural, no hacen sino producir leyes individuales ${ }^{28}$. Por último, el «sentido literal» de la ley no tiene nada que ver con la pluralidad de sentidos resultantes por la ambigüedad de las palabras, entre otros motivos. Hobbes corrige expresamente cualquier margen de duda: «si por letra se entiende el sentido literal, entonces la letra y la sentencia o intención de la ley son la misma cosa, porque el sentido literal es aquél que el legislador se proponía significar por la letra de la ley. En efecto, se supone siempre que la intención del legislador es la equidad (...). Por consiguiente, si el texto de la ley no autoriza plenamente una sentencia razonable (el intérprete-juez) debe suplirlo con la ley de naturaleza» ${ }^{29}$.

La modernización de la sociedad y el racionalismo determinan la profundización de la ficción hermenéutica de la voluntad del legislador. En la explicación teórica de Hobbes, que acaba de ser expuesta, comienza a perfilarse una dimensión fuerte de la hipótesis del legislador racional. Además,

25 HOBBES, Leviatán, cit., p. 223-4.

26 Ibídem, p. 222.

27 Ibídem, p. 226.

28 Ibídem, pp. 226 ss.

29 Ibídem, p. 229-30. Al respecto cabe recordar que ya para Aristóteles ser equitativo es «mirar no a la ley sino al legislador. Y no a la letra sino a la intención del legislador, y no al hecho, sino a la intención, y no a la parte, sino al todo...», ARISTÓTELES, Retórica, ed. y trad. A. Tovar, Madrid, IEP, 1971, I, 13 (1374 b). Cfr. también, ibídem, I, 15 (1375 a. y 1375 b.). Sobre la diferente consideración y actitud de Hobbes ante las obras de Aristóteles y su estudio de la retórica, cfr. Leo STRAUSS, The Polotical Philosophy of Hobbes. Its Basis and Its Genesis trd. del manuscrito alemán Elsa M. Sinclair, Chicago, The Univ. of Ch. Press, 1963, pp. 33 ss. Ollero, por su parte, ha hablado en este punto de recuperación positiva de la equidad y la ley natural, cfr. Andrés OLLERO, Hobbes y la interpretación del derecho, en Interpretación del derecho y positivismo legalista, Madrid, EDERSA, 1982, pp. 60 ss. 
y es importante subrayarlo, el voluntarismo racionalista o moderno traduce la fe política de las nuevas clases dominantes en la seguridad y la capacidad creadora de la letra escrita en reglas específicas de la metodología hermenéutica. Así, progresivamente se van a ir marginando las esperanzas de estabilidad y renovación depositadas en la pura objetividad del derecho de la razón para irse consolidando las explicaciones que propugnan la supremacía absoluta de la ley positiva. Como consecuencia se defiende la necesidad de que la ley se integre desde sí misma. Todo ello conduce a proyectar sobre la escritura la capacidad para fijar el espíritu, eludiendo la arbitrariedad e identificando el mandato del legislador como la manifestación asertiva clara y terminante de un contenido volitivo racional. Pufendorf, a medio camino entre Grocio y Hobbes en tantos aspectos, anuncia en este punto las repercusiones de la idea de seguridad. Al hacerse externa la obligación jurídica, la necesidad de alcanzar una certeza absoluta descansa en la objetividad de la interpretación ${ }^{30}$. En este sentido, habría que entender que la seguridad no es tanto la consecuencia como el antecedente del giro teórico que anuncia el positivismo jurídico y la autonomía del derecho frente a la moral. La objetividad y la generalidad dejan de ser meros imperativos epistemológicos o dogmáticos y asumen una dimensión jurídicopolítica. Jean Domat recoge y da una salida terminante a este lugar común de la época en la dirección de la «ciencia del derecho positivista» y la codificación ${ }^{31}$. Para Domat, también, la univocidad no es una consecuencia agregada, sino una necesidad que determina el punto de partida de su consideración: «todas las leyes, ya naturales, ya arbitrarias -las leyes positivas-, tienen un uso fijo, al cual las determina la justicia universal que es su espíritu. Por lo tanto, su aplicación debe hacerse discerniendo lo que exige este espíritu, que en las primeras es la equidad natural y en las segundas la voluntad del legislador» ${ }^{32}$. Las leyes tienen que tener un uso fijo para que la generalidad de las mismas sea preservada. Pero, además, se pretende que

30 Samuel PUFENDORF, De la obligación del hombre y del ciudadano según la ley natural en doslibros, trd. Lelia de Ortiz, Univ. de Córdoba (Argentina), 1980, lib, I, XVII, 1: «en los asuntos o cuestiones ordenadas o prescritas por la autoridad, el hombre no está obligado más allá del propósito o la intención de dicha autoridad, y en los asuntos o materias que el hombre elige obligarse, no quedará comprometido más allá de lo que fue su intención. Y, sin embargo, como no podemos juzgar la intención de otro, salvo por las acciones y signos que impresionan en nuestros sentidos, en los tribunales de los hombres se considera al individuo, consiguientemente, como obligado sólo a lo que puede sugerir una seria interpretación de tales indicadores. De aquí que, para una adecuada comprensión de las leyes, como así también de los pactos y para el cumplimiento del deber que ellas involucran es de suma importancia establecer las reglas de una buena interpretación, especialmente en lo que hace a las palabras que constituyen el signo más común». Esto aparte, Pufendorf postula la necesidad de alcanzar el «verdadero significado», (verum sensum, rectique sensus, genuinum sensum) y abunda en los criterios hermenéuticos expuestos por Grocio, cfr. PUFENDORF, De Iure Naturae et Gentium, G. Moscovius (Ed.), Frankfurt a. M., Minerva, 1967, lib. V, cap. XII.

31 Cfr. Giovanni TARELLO, Storia della cultura giuridica moderna, I: Assolutismo e codificazione del diritto, Bologna, Mulino, 1976, pp. 156 ss.

32 Jean DOMAT, Las leyes civiles en su orden natural, tomo I, trd. F. Villarubias y J. Sardá, Barcelona, 1844, p. 86. 
la univocidad no dependa de ningún motivo ajeno a la ley, esto es, que la ley pueda integrarse desde sí misma. Por eso, Domat, en lo que concierne a la metodología hermenéutica, asume plenamente el paradigma sistemático ${ }^{33}$. Por eso, también, la fe de Domat en la escritura: «la ley debe ser escrita, a fin de que la escritura fije su sentido y determine al espíritu a la justa idea de lo que está mandado, y para que no sea a cada uno formarla según la interpretación que el mismo la pueda dar» ${ }^{34}$.

\section{III}

Para concluir esta rápida revisión de la genealogía de la voluntad del legislador como ficción hermenéutica, voy a centrarme en un autor de transición. La obra de Jeremy Bantham rebasa el planteamiento de las propuestas teóricas que se han estudiado hasta ahora. Bentham deja de ser antecedente de una mentalidad jurídica para verse envuelto en ella. No sólo comparte los ideales iluministas que impulsan la codificación en otros ámbitos culturales, sino que incluso desarrolla algunos de sus elementos fundamentales. Y ello tanto en lo que atañe a sus investigaciones sobre la ciencia de la legislación como en lo que supone su importante contribución a pensar modernamente la sociedad disciplinaria ${ }^{35}$. Pero aquí no entraremos en estas cuestiones más generales. No es que crea que los postulados de la sociedad disciplinaria o la ciencia de la legislación sean radicalmente escindibles de las concepciones hermenéuticas. Simplemente, se trata de que teniéndolos presentes no estén demasiado presentes. Al menos no tan presente que puedan marginar la atención que requiere su labor de integración teórica del viejo esquema de la ideología hermenéutica que se ha expuesto en los dos apartados anteriores.

En el comienzo de su importante libro Of Laws in General, concebido como continuación de los Principios aunque inédito hasta fechas muy recientes ${ }^{36}$, Bentham propone una definición del derecho que puede ser considerada como el paradigma, o mejor, como círculo de referencia en el que se enmarcan los aspectos particulares de su elaborada teoría general del derecho. Bentham explica la ley concibiéndola como la expresión de la voluntad de un soberano. Dado que esa voluntad tiene que ser expresada mediante signos, ello va a realzar el papel del lenguaje en su comprensión de la me-

33 Ibídem, p. 90-1.

34 Ibídem, p. 80.

35 Sobre estas cuestiones, cfr. Jeremy BENTHAM, Tratados de legislación civil y penal, ed. Magdadela Rodríguez (se trata de la traducción de la edición francesa que realizó Ramón Salas en 1821), Madrid, EN, 1981. En buena medida, la actualidad de Bentham se debe a los trabajos de Foucault, que destacan críticamente una faceta de la obra de Bentham que había pasado prácticamente desapercibida. Cfr. Michel FOUCAULT, La verdad y las formas jurídicas, trd. E. Lynch, Barcelona, Gedisa, 1980, pp. 117 ss.; ID., Vigilar y castigar, trd. A. Garzón, Madrid, Siglo XXI, 1978, pp. 203 ss.

$36 \mathrm{Al}$ respecto, pueden verse Herbert L. A. HART, «Introducción» a Jeremy BENTHAM, Of Laws in General, H. L. A. Hart (Ed.), University of London, 1970, pp. XXI ss.; HART, «Bentram's 'Of Laws in General'», Rechtstheorie 2/1 (1971), pp. 55-66; Karl OLIVECRONA, «The Will of the Sovereign: Some Reflections on Bentham's Concept of 'A Law'», American Journal of Jurisprudence, 20 (1975), p. 95. 
todología jurídica. En este sentido, más que novedosa, su definición puede ser considerada como una recapitulación y armonización de concepciones anteriores a la vista de las tendencias que sigue el desarrollo de las técnicas legislativas. Así, considera a la ley como «un conjunto de signos declarativos de una voluntad concebida o adoptada por el soberano en un Estado» ${ }^{37}$. Por otro lado, en la obra de Bentham culminan las transformaciones modernas que inciden sobre una forma de construir la objetividad cuya base fundamental es la presuposición según la cual los signos están en lugar de algo, siendo ese algo un contenido intelectual: la razón escrita, primero, la voluntad del legislador, después. Las novedades consisten más en la forma de explicar el logro de la objetividad y los procedimientos adecuados para alcanzarla que en esa consideración fundamental a la que se acaba de aludir. Como sea, Bentham, definitivamente, dota de una explicación moderna a la vieja idea del alma de la ley. La racionalidad se desplaza desde el texto a la hipótesis de un legislador racional. En este sentido, en la línea de lo apuntado por la tradición racionalista, desde Grocio a Hobbes, los signos lingüísticos de la ley, como en cualquier otro uso lingüístico, expresarían un estado mental interno. Un estado mental que, en el supuesto de la ley, se configura específicamente como una volicion: the state of legislator's mind, an internal state of the will ${ }^{38}$.

Bentham desarrolla una teoría que integra la consideración del significado de la ley como un mandato con la manifestación asertiva de un contenido volitivo. Al tiempo que construye su lógica de la voluntad, Bentham identifica el significado dentro de lo que en general es la expresión de un estado mental mediante signos. Los procedimientos analíticos y las distinciones de Bentham pueden parecernos un poco toscas ${ }^{39}$, pero llegar a tales conclusiones supone entre otras cosas adelantarse en muchos años a la conciencia de su tiempo. Algo que, como en el caso de Hobbes, ha de ser convenientemente valorado. Como punto de partida, Bentham considera que la lógica de la voluntad es una lógica imperativa. Esto es, que la forma lingüística válida para expresar la voluntad concerniente a una conducta que deberá ser observada es la forma imperativa ${ }^{40}$. Ahora bien, debemos ser precavidos y no acercarnos a esta afirmación con prejuicios actuales. Bentham pone especial cuidado en conciliar esta afirmación con la relevancia normativa y hermenéutica del contenido intelectual de la ley. El significado de cualquier signo lingüístico expresaría siempre un estado mental, los signos manifestarían siempre algo que ha sido concebido o pensado. Toda expresión

BENTHAM, Of Laws in General, cit., p. 1.

Cfr. ibídem, pp. 98, 97, 152 ss.; también, BENTHAM, An Introducion to the Principles of Morals and Legislation, J. H. Burns y H. L. A. Hart (Eds.), Univ. of London, 1970 , p. 299.

Con todo, no sería tan radical como Hart, cfr. HART, Essays on Bentham. Studies in Jurisprudence and Political Theory, Oxford, Clarendon Press, 1982, pp. 248 ss.

BENTHAM, Of Laws in General, cit., pp. 154, 104 ss. Sobre la lógica de la voluntad de Bentham y su alcance actual, pueden verse Joseph RAZ, The Concept of a Legal

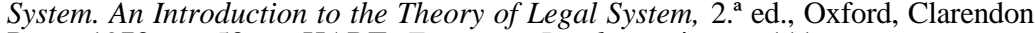
Press, 1973, pp. 53 ss.; HART, Essays on Bentham, cit., pp. 111 ss. 
lingüística tiene como referencia -diríamos hoy- un estado mental que exterioriza bien sea como manifestación de una creencia o bien como manifestación de una volición. Según esto, cualquier locución que exprese algo tiene que ser un aserto ${ }^{41}$. ¿Dónde radican, pues, las particularidades del significado de la ley o de cualquier locución que exprese un contenido volitivo? Sucintamente, en una especie de valor añadido que diferenciaría un aserto que declara una voluntad respecto de otro que expresa una creencia. Ese valor añadido puede adoptar formas diversas. Bentham enumera varias de ellas e incluso señala que esa forma puede ser elíptica -se refiere a la forma verbal ordinaria del imperativo ${ }^{42}$.

Más allá de su transcendencia filosófico-lingüística, lo anterior tiene un doble orden de consecuencias. En primer lugar, tras este planteamiento late una concepción previsora de la ley. Al conjugar la forma del imperativo con la relevancia de su contenido intelectual, Bentham completa su definición del derecho expuesta más arriba. Así, ahora puede decir que la ley es «la declaración de voluntad ... concerniente a la conducta que deberá ser observada en un cierto caso por una persona o clase de personas que en el supuesto en cuestión estén o se suponga que están sujetos al poder de un soberano» ${ }^{43}$. Por otra parte, en segundo lugar, Bentham resalta la dimensión intelectual de la búsqueda del significado de la ley. La labor hermenéutica del intérprete ha de buscar identificar perfectamente un contenido semántico, ideas abstractas, un estado mental que se concibe como la voluntad del legislador. Con lo cual, la corrección hermenéutica se configura en base a la correlación de dos contenidos intelectuales. Bentham considera terminantemente que sólo son correctas las interpretaciones que expresan la voluntad del legislador. Pero ello no impide que, al darse por supuesto la racionalidad del legislador, esa voluntad pueda ser integrada racionalmente, «interpretándola», siempre y cuando ello no conlleve discrecionalidad ${ }^{44}$. En este punto, Bentham intenta un difícil equilibrio entre los postulados político jurídicos de la ilustración -plenitud, seguridad jurídica, separación de poderes, igualdad, etc.- y la convicción práctica de las dificultades que conlleva asegurar mediante la expresión adecuada, sin fisuras ni opacidades, la racionalidad ucrónica y universal de los imperativos legales.

\section{CONCLUSIONES}

El desenvolvimiento de la semántica de la voluntad, sobre todo a la luz de los últimos desarrollos estudiados, anuncia ya la consolidación «científica» del método deductivo de la concepción tradicional durante la primera

41 BENTHAM, An Introduction to the Principles, cit., pp. $299 \mathrm{~s}$.

42 Ibídem, pp. 299 s.; BENTHAM, Of Laws in General, cit., p. 154. Para más detalles sobre este punto puede verse, HART, Essays on Bentham, cit., p. 248.

43 BENTHAM, Of Laws in General, cit., p. 1.

44 Ibídem, pp. 156 ss.; 239 ss. 
mitad del siglo XIX ${ }^{45}$. Aunque no cabe ninguna duda sobre la importancia de la prolongación «científica» de esta ficción hermenéutica que lleva a buscar la voluntad del legislador tras la letra de la ley, voy a concluir aquí esta investigación limitándome a subrayar algunos detalles o consecuencias derivadas de la misma. Quizá no sea necesario advertir que no se trata tan sólo de clarificar el valor de una vieja reliquia. Es cierto que la atomización y la dispersión epistemológica de la ciencia jurídica actual también ha afectado a esta ficción hermenéutica que se rechaza, transforma o sustituye. Pero, de todas formas, algunas de sus consecuencias más importantes mantienen una presencia decisiva en la praxis y en la teoría de la interpretación jurídica de la dogmática. Se trata, a veces, de una presencia, difusa, barrosa. Otras, las mutaciones de los apoyos teóricos que las explican hacen difícil su reconocimiento. Pero, en todo caso, con independencia de todas las novedades y de todas las transformaciones, hay algo así como un talante que perdura aún hoy en día.

A pesar de su carácter fragmentario, la mínima revisión genealógica efectuada lleva a constatar, de entrada, la importancia del papel que juega en la ideología hermenéutica la semántica de la voluntad. La presuposición (postulado o hipótesis teórica) de que existe un «sentido objetivo» depositado en la letra de la ley y su identificación, primero, con una instancia racional profunda y, después, a medida que culmina el proceso de estatalización de la ley, con la voluntad del legislador determina una concepción ideológica según la cual las interpretaciones autorizadas o correctas expresarían sin opacidad ni distorsión alguna el pensamiento o la voluntad incorporada como instancia espiritual tras la letra de la ley, en su significado. La función de este postulado que presupone tras la expresión un contenido semántico que consiste en ideas abstractas, el sentido objetivo de la ley, es múltiple. En primer lugar, la hipótesis de esa instancia racional profunda permite dotar de una cierta flexibilidad la tarea hermenéutica. Una flexibilidad $d o g$ mática que hace posible superar las dificultades o los silencios del texto e, incluso, las contradicciones de la letra con las creencias autorizadas del intérprete sobre lo que debiera o debiera haber sido querido o pensado por el legislador. El objetivo de la actividad hermenéutica, según esto, tendería a averiguar y comprender el significado racional de la ley y, dado que se acepta como postulado que el legislador y el alma o el pensamiento de la ley son racionales, el intérprete no podrá llegar a una conclusión hermenéutica que se aparte de los cánones de racionalidad aceptados dentro del orden dogmático. También se desprende de lo anterior la posibilidad de acomodar el significado de la ley a las necesidades históricas y al contexto de su aplicación. Por otra parte, mediante la ficción hermenéutica que se viene considerando, las producciones hermenéuticas se ligan a la ley con una suerte de

45 Las tres direcciones más significativas de la metodología jurídica del siglo XIX reciben la influencia de la «semántica de la voluntad» en sus propios orígenes. Cfr., al respecto, Friedrich K. von SAVIGNY, Sistema de Derecho Romano actual, trd. J. Mesía

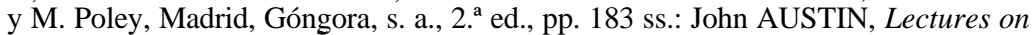
Jurisprudence, tres vol., New York; Burt Franklin, 1970, vol II: pp. 121 ss., 331 ss.; vol III: 229 ss.: Julien BONNECASE. L'École de l'Exégèse en Droit Civil, París, E. de Boccard Ed., 1924, pp. 128 ss. y 131 ss. 
vínculo hipostático. Como consecuencia, se niega hasta la mera posibilidad de interferencias u opacidades, ya sean de carácter subjetivo u objetivo, y se inscribe la decisión hermenéutica directamente en la ley. Además, mediante ese vínculo sublime, en la aplicación de la ley, se adscribe al legislador la voluntad que decide el caso concreto. De esta manera, la inscripción de las ejecuciones hermenéuticas en la voluntad de un legislador ideal, racional y dotado de una autoridad absoluta, legítima y justifica las interpretaciones autorizadas. Por último, aunque no por ello con menor transcendencia, la ficción hermenéutica de la voluntad del legislador legítima al intérprete para corregir los defectos superficiales de la ley. Plenitud, armonía, generalidad e intemporalidad son ideales que nacen más allá del texto de la ley. Son el resultado de una sobre-codificación transcendente, realizada desde el alma de la ley o la voluntad del legislador. Pero, en tanto en cuanto se mantiene la fe en ese núcleo profundo de racionalidad omnicompresiva y perfecta, se mantiene la eficacia de un canon hermenéutico fundado en la coherencia y la plenitud ucrónica del sentido objetivo de la ley. Las apariencias de ambigüedad, insuficiencia o contradicción sólo existirían en los umbrales de la expresión. 